\title{
Correction to: Lightweight Printed Dipole Antenna Array With $3 \times 2$ Beamforming Network for Wide UAV Communication Coverage
}

\author{
Dong-Geun Seo ${ }^{1} \cdot$ Jeong-Soo Park ${ }^{1} \cdot$ Gun -Ki Lee ${ }^{1} \cdot$ Wang-Sang Lee $^{1}$ (I)
}

Published online: 20 July 2020

(c) The Korean Institute of Electrical Engineers 2020

\section{Correction to: Journal of Electrical Engineering \& Technology (2020) 15:1769-1773 \\ https://doi.org/10.1007/s42835-020-00455-0}

Unfortunately the funding note to this article has been omitted. It should be:

Funding This work was supported in part by the Ministry of Science and ICT (MSIT), South Korea, through the Institute for Information and Communications Technology Promotion (IITP)-A study on a small antenna system for vehicle supporting wide elevation angle-under Grant 2017-0-00795 and in part by the Ministry of Trade, Industry and Energy (MOTIE), South Korea, through the Human Resources Program in Energy Technology of the Korea Institute of Energy
Technology Evaluation and Planning (KETEP) under Grant 20194030202430.

Publisher's Note Springer Nature remains neutral with regard to jurisdictional claims in published maps and institutional affiliations.
The original article can be found online at https://doi.org/10.1007/ s42835-020-00455-0.

Wang-Sang Lee wsang@gnu.ac.kr

1 Department of Electronic Engineering/Engineering Research Institute (ERI), Gyeongsang National University (GNU), 501, Jinju-daero, Jinju-si, Gyeongsangnam-do 52828, Republic of Korea 